\title{
APROPRIAÇÃO DA RIQUEZA DO TRABALHO E DA NATUREZA PELO CAPITAL NO BRASIL: REFLEXÕES A PARTIR DE KARL MARX E FLORESTAN FERNANDES ${ }^{1}$
}

\author{
Tainara Fernandes Machado ${ }^{2}$ \\ Guilherme Luiz Krucinski Tortelli ${ }^{3}$
}

\begin{abstract}
RESUMO
O trabalho ao transformar a natureza agrega/cria valor. Esse que no capitalismo é apropriado pelos capitalistas e, na história do Brasil, que foi de escravidão e autoritarismo, criou uma sociedade racista, excludente e exploradora; sem pudor para com ostrabalhades e a natureza. A partir de Karl Marx discutimos a relação sociedade $x$ natureza e o papel do trabalho; e, com Florestan Fernandes, as particularidades da dominação capitalista no Brasil. Após, analisa-se criticamente os retrocessos dos direitos trabalhistas e sociais gerados pelas reformas promovidos pelo governo de Michel Temer e referendada por empresários, banqueiros, militares e classe média. Estes que, até o momento, prepararam o caminho para Bolsonaro poder ampliar a exploração tanto da natureza, quanto dos trabalhador.
\end{abstract}

Palavras-chave: Karl Marx. Florestan Fernandes. Trabalho. Natureza. Exploração.

\section{SUMMARY}

Work in transforming nature adds value. This, which in capitalism is appropriated by the capitalists, and in the history of Brazil which was of slavery and authoritarianism, created a racist, exclusionary and exploitative society; without modesty towards the workers and the nature. From Karl Marx we discuss the relationship between society and nature and the role of work; and with Florestan Fernandes the particularities of capitalist domination in Brazil. After a critical analysis of the retreats of labor and social rights by the reforms promoted by the government of Michel Temer and supported by entrepreneurs, bankers, military and middle class. These have so far prepared the way for Bolsonaro to expand the exploration of nature and workers.

Keywords: Karl Marx. Florestan Fernandes. Work. Nature. Exploration.

\footnotetext{
${ }^{1}$ Uma versão deste trabalho foi apresentada em Braga, Portugal no Colóquio Internacional Marx 2018, 4 a 7 dezembro de 2018.

${ }^{2}$ Educadora Social, Pedagoga pela Faculdade de Educação e Mestre em Educação pelo Programa de Pós-Graduação em Educação da Universidade Federal do Rio Grande do Sul UFRGS, Porto Alegre - Rio Grande do Sul - Brasil. E-mail: tainara.fernandesmachado@gmail.com.

${ }^{3}$ Historiador pelo Instituto de Filosofia e Ciências Humanas e Graduando em Ciências Jurídicas e Sociais pela Faculdade de Direito, ambos da Universidade Federal do Rio Grande do Sul UFRGS - Porto Alegre - Rio Grande do Sul - Brasil. Atua na área de contabilidade especializada em Direito Trabalhista E-mail: guilhermetortelli@hotmail.com.
} 


\section{INTRODUÇÃO: OS TRABALHADORES NO CONTEXTO ATUAL DO CAPITALISMO BRASILEIRO}

Um das formas de os capitalistas aumentarem a riqueza produzida, que não é paga aos trabalhadores, é fazendo-os trabalhar mais; e, portanto, produzindo mais, seja pela coerção e pela pressão gerada pelas inovações tecnológicas. Outra forma é reduzir o "custo" do trabalho, que pode ser dar de forma direta ou indireta: diretamente pelo rebaixamento remuneratório, a partir de retirada de direito, benefícios, etc.; ou indiretamente, em que pesa o custo de vida, da inflação, etc. Os reajustes do salário são feitos (quando o são!) abaixo da inflação, e, assim, consequentemente, ao longo do tempo o "poder aquisitivo" do salário diminui.

Esses recursos são utilizados pelos capitalistas no Brasil, sendo que existemainda muitos outros. Por exemplo, a enorme massa de trabalhadores sem emprego (que buscam emprego ou que desistiram de buscá-los, número que extrapola os dados oficiais de desemprego), a exclusão e a miséria que atinge outro grande número de pessoas, a "mentalidade escravista" e racista incrustada nas relações sociais, etc. Essas nos levam ao questionamento e à judicialização dos mínimos direitos ${ }^{4}$ ou benefícios conquistados.

Tais situações tendem a ser ampliadas quando o capitalismo nacional ou internacional enfrenta crises, fazendo baixar a produção global de riqueza e acirrando a disputa entre os diferentes e diversos capitais na apropriação da riqueza produzida. $\mathrm{Na}$ cadeia produtiva, quanto mais produzirem os trabalhadores, ou, mais rica e sem custos é a exploração da natureza (dos recursos naturais), mais lucro é adquirido individualmente pelo capitalista e, portanto, faz a manutenção de sua posição nesta luta feroz com seus concorrentes.

\footnotetext{
4 Ver Lei 150/2015 lei dos empregados domésticos, in: https://www.youtube.com/watch?v=qnnVUHigdiA; mas que, depois de três anos, mais de $70 \%$ dos trabalhadores ainda são informais: https://extra.globo.com/noticias/economia/lei-dadomestica-completa-tres-anos-mas-informalidade-judicializacao-sao-desafios-22760270.html, acesso 14.11.2018.
} 
Durante as últimas décadas, em decorrência das demandas do mercado internacional (principalmente da China), e internamente, por políticas de distribuição de renda (bolsa família, aumento do salário mínimo ${ }^{5}$, etc.) desenvolvidas nos governos Lula e primeiro de Dilma, melhorou-se a vida e efetivaram-se direitos dos trabalhadores e, também, excluídos. Ao aumentar o "poder aquisitivo", seja através dessas políticas, ou pela criação de empregos gerada pelos investimentos em infra-estrutura, ocorreu a injeção derecursos na economia, reforçando o consumo e a produção de riqueza. No entanto, a crise econômica do capitalismo internacional se abateu sobre essa realidade, estando relacionada com o crescimento da extrema direita, que possui vieses fascistas, em alguns casos. Esses elementos levaram o Brasil, mas também outros países da América Latina, à crise que culminou com a derrubada de "governos progressistas" que predominaram desde os anos 2000.

O "governo progressista" brasileiro, e a sua aliança e financiamento, entrou em crise anos após 2008, que é o ano que marca a crise do capitalismo nos Estados Unidos, gerado pela especulação imobiliária, espalhando-separa a Europa e tendo como consequência a redução das demandas por parte da China. Ao mesmo tempo, cresce, a partir de então, a ofensiva norte-americana contra os governos progressistas, derrubando-os com apoio das elites, juízes e militares através de golpes (Haiti, 2004; Honduras, 2009; Paraguai, 2012), ou pela eleição (Argentina, 2015; Equador, $2017^{6}$, etc.). No Brasil, em 2016, com o golpe que se transvestiu de impeachment e, recentemente, com a eleição de Jair Bolsonaro (2018), que se valeu da assessoria de Steve Bannon - o estrategista de Donald Trump. Ou seja, a direita e o fascismo assumem a hegemonia na América Latina (SANTOS, 2018) ${ }^{7}$.

Com o golpe de 2016, a destruição social e trabalhista promovida por Michel Temer na aplicação do receituário neoliberal auxiliou para que um

\footnotetext{
${ }^{5}$ STIGLITZ, Joseph. Los datos son abrumadores. Subir el salario mínimo no dãna al empleo.EI País, 11 de noviembre 2018, p.54 [Economia y Trabajo]. Edição impressa.

${ }^{6} \mathrm{O}$ caso do Equador é atípico pois eleito como progressistas dando continuidade e apoiado pelo governo anterior, vira a casaca depois de assumir o governo. Inclusive, desonrando o próprio nome: Lenín Moreno.

7 Disponível em: <https://www.sul21.com.br/opiniaopublica/2018/10/as-democracias-tambemmorrem-democraticamente-por-boaventura-de-sousa-santos/>. Acesso em: 08 nov. 2018.
} 
outsider, como Bolsonaro, pudesse ser eleito em fins de 2018. No entanto, pesou, ainda, diríamos, a criminalização pela mídia capitalista da esquerda, e sua associação com a corrupção; a deslegitimação tanto dos meios de comunicação e da justiça por medidas seletivas contra políticas sociais e econômicas diversas ao receituário neoliberal, quanto, por fim, o uso de recursos midiáticos (whatsapp, etc.) a partir da expertise de Steve Bannon junto a setores "sensíveis" a determinadas temáticas bombardeadas por fake news focalizadas, como os evangélicos e outros grupos (militares, ruralistas ${ }^{8}$, etc.).

A partir desse cenário político e social brasileiro, está configurando-se como possíveis medidas do novo governo a ampliação da exploração do trabalho e dos trabalhadores como analisamos adiante, em relaçãoà reforma trabalhista e da natureza. Mas, também, privatizações, retirada de direitos, ampliação do tempo e contribuição para as aposentadorias, etc. Sabemos que, para efetivá-las, haverá resistência. E, nesse sentido, outra tendência do governo atual e seus ministros é inspirarem-se no que os capitalistas desenvolveram no Chile durante a ditadura de Augusto Pinochet":

Por qué la Escuela de Chicago y sus teorías económicas ultraliberales abonan mejor las dictaduras y en los modelos autoritarios que en las democracias consolidadas? Posiblemente porque para ser puestas en práctica, se necesita que las resistencias ciudadanas ante la desigualdad que generan no tenga cauces fuertes para manifestar en el seno de la sociedad civil (ESTEFANÍA;JOAQUÍN, 2018) .

Portanto, evidencia-se que Michel Temer preparou o terreno para as reformas, não obtendoa força necessária devido à resistência popular e, também devido à aproximação das eleições de 2018. E, com a eleição de Bolsonaro - e, consequentemente, seus asseclas Chicago Boys et. caterva, militares, evangélicos e o grande empresariado - tentará radicalizar a redução

\footnotetext{
8 "Naban Garcia dispara whatsapp contra Onix", in Revista Fórum (7 novembro), Piauí (6 novembro), onde o dirigente da UDR detona o ministro de Bolsonaro. O interessante é o grupo de wattsap da UDR!

${ }^{9}$ Isto porque, não somente Paulo Guedes é um Chicago boy, como também já manifestou-se como positiva aquela experiência, e ainda, parece que a primeira visita internacional de Bolsonaro será o próprio Chile. https://noticias.r7.com/brasil/por-que-a-primeira-viagem-debolsonaro-sera-ao-chile-07112018, acesso 14.11.2018; Joaquin Estefanía, Escuela de Chicago y autoritarismos, EI Pais, caderno IDEAS, 28 outubro de 2018, p.8.
} 
do "custo do trabalho" (lembram-se do custo Brasil?). E essa, inclusive, preparando-se em caso de resistência popular, com as atualizacoes da lei antiterrorista que foi implementrada no governo de Dilma Roussef, e/ou criando grupos especiais de monitoramento da sociedade civil. ${ }^{10}$

\title{
MARX, O TRABALHO E A NATUREZA
}

O trabalho é a ação humana (do trabalhador) de transformação da natureza, seja criando coisas úteis (valores de uso) a partir de determinadas matérias-primas, seja a transformação da própria terra que ao arar, plantar e que depois de germinar possibilita a colheita de frutos e alimentos. No entanto, tais relações mudam através dos tempos e dos lugares, pois diferentes são/foram as relações entre comunidades "primitivas" ${ }^{11}$, ou mesmo entre tribos indígenas com a natureza daquelas que já se organizavam em cidades onde vivia o rei, imperador ou o faraós, daquelas cidades atuais no capitalismo que são centros estratégicos para o capital $^{12}$. No extremo sul do Brasil, o Observatório dos Conflitos assim define tal perspectiva, num sentido mais amplo:

\begin{abstract}
Nas pesquisas que realizamos no extremo sul do Brasil e no observatório dos conflitos nos orientamos "pela perspectiva, de que no núcleo dos conflitos está a disputa pela riqueza produzida, pela apropriação das terras e pelas políticas (ou falta delas) pelos governos. A riqueza, por sua vez, decorrente da transformação, apropriação e significação da natureza está no centro das questões políticas e sociais na disputa entre as classes e grupos sociais (JornalECO, editorial, O momento atual: o Brasil na encruzilhada, edição numero 6 , inverno de 2018, p.2).
\end{abstract}

Partindo desses aspectos gerais, mas focando mais diretamente na produção de Marx, a seguir detalharemos como o mesmo discute a relação do

\footnotetext{
${ }^{10}$ Sobre a nova lei antiterrorista ver: https://www.cartacapital.com.br/revista/1029/criminalizaros-movimentos-sociais-e-destruir-os-pilares-da-democracia; e Temer cria força-tarefa de inteligência com assento permanente para militares, in: https://brasil.elpais.com/brasil/2018/10/31/politica/1540948811 126055.html. Acesso em: 14 nov.2018.

${ }^{11}$ MARX, Karl. Formações Econômicas Pré-Capitalistas. 6ª ed. São Paulo: Paz e Terra, 1991; Karl Marx, Grundrisse - manuscritos econômicos de 1857-1858: esboços da crítica da economia política. São Paulo: Boitempo, 2011.

12 LOWY, Michael. A cidade, lugar estratégico do enfrentamento das classes, Margem Esquerda $n^{\circ} 08$, Boitempo: São Paulo, 2006. Ou versão espanhol, online: <https://www.herramienta.com.ar/articulo.php?id=1138>. Acesso 11 nov. .2018.
} 
trabalho com a natureza, e do salto de qualidade desta relação no capitalismo, quando de um lado aumenta a produção devido à divisão do trabalho e outras medidas criadas pelos capitalistas e seus funcionários; de outro, amplia a exploração, o embrutecimento, a alienação daqueles que produzem.

Nos Manuscritos econômico-filosóficos ${ }^{13}$, na parte intitulada "Trabalho estranhado e propriedade privada" junto com as referências da natureza e sua relação com o trabalho e a sociedade, diz Marx:

\begin{abstract}
O trabalhador nada pode criar sem a natureza, sem o mundo exterior sensível (sinnliche). Ela é a matéria na qual o seu trabalho se efetiva, na qual [o trabalho] é ativo, [e] a partir da qual e por meio da qual [o trabalho] produz. Mas como a natureza oferece o meio de vida, no sentido de que o trabalho não pode viver sem objetos nos quais se exerça, assim também oferece, por outro lado, o meio de vida no sentido mais estrito, isto é, o meio de subsistência física do trabalhador mesmo. (MARX, In ANTUNES, 2004, p.178)
\end{abstract}

No entanto, no capitalismo, quanto mais "o trabalhador se apropria do mundo externo, da natureza sensível, por meio do seu trabalho, tanto mais ele se priva dos meios de vida" (MARX, 2004, P.178), pois ele não é dono nem do produto de seu trabalho, nem dos meios para a realização deste. Ou seja, o processo de "transformar a natureza", no capitalismo, é também um processo de produção da separação dele (homem) enquanto ser da natureza a uma natureza exterior a ele mesmo. gerando um "estranhamento" do trabalhador no processo total do da transformação da natureza ou da materia-prima.

Disso, do ponto de vista físico, diz Marx, tanto o homem quanto o animal, "vive (m) da natureza inorgânica" mas, "quanto mais universal o homem (é) do que o animal, tanto mais universal é o domínio da natureza inorgânica da qual ele vive" (MARX, 2004, p.182, grifos nossos). Porém, contrapõe que

Praticamente, a universalidade do homem aparece precisamente na universalidade que faz da natureza inteira 0 seu corpo inorgânico, tanto na medida em que ele é um meio de vida imediato, quanto o objeto/matéria é o instrumento de sua atividade vital. A natureza é o corpo inorgânico do homem,

\footnotetext{
${ }^{13}$ Karl Marx. Manuscritos econômico-filosóficos (fragmento da parte final), escrito entre março e setembro de 1844, em Paris. Ver, edição Boitempo, São Paulo (tradução de Jesus Ranieri, UNESP). Este texto foi publicado em ANTUNES, Ricardo (org.). A Dialética do Trabalho - escritos de Marx e Engels. São Paulo: Expressão Popular, 2004.
} 
a saber, a natureza enquanto ela mesma não é corpo humano. O homem vive da natureza, significa: a natureza é o seu corpo, com o qual ele tem de ficar num processo contínuo para não morrer. Que a vida física e mental do homem está interconectada com a natureza não tem outro sentido senão que a natureza está interconectada consigo mesmo, pois 0 homem é uma parte da natureza (MARX, 2004, p.182-183).

No entanto, com o capitalismo, ocorre uma ruptura gradual -por vezes mais acelerada ${ }^{14}$ - do primitivo vínculo familiar entre a agricultura e a manufatura, da aglutinação das populações em centros urbanos, a produção em grande indústrias com divisão do trabalho em seu interior e na sociedade, dentre outros resultados do desenvolvimento do capitalismo "perturba o metabolismo entre o homem e a terra" 15 . Por outro lado, a agricultura capitalista também, produz efeitos nefastos nessa relação:

Al igual que en la industria urbana, en la moderna agricultura la intensificación de la fuerza productiva y la más rápida movilización del trabajo se consiguen a costa de devastar y agotar la fuerza de trabajo del obrero. Además, todo progreso, realizado en la agricultura capitalista, no es solamente un progreso en el arte de esquilmar al obrero, sino también en el arte de esquilmar la tierra, y a cada paso que se da en la intensificación de su fertilidad dentro de un período de tiempo determinado, es a la vez un paso dado en el agotamiento de las fuentes perenes que alimentan dicha fertilidad (MARX, 1986, p.454).

Assim, o capitalismo ao crescer tendo por base as cidades sobre 0 campo, cresce o predomínio da população urbana, e consequentemente, suas necessidades alimentares, etc.; mas também, as forças produtivas concentradas nessas, perturba o metabolismo entre o homem e a terra e as águas, o qual prejudica a fecundidade da terra, esgota os rios e mares de sua piscosidade, além de jogar dejetos nos mesmos; e prejudica, assim, seja pelas condições criadas (leia-se destruídas) seja pelos processo de trabalho a saúde do trabalhador.

A pequena propriedade, quando não disponível para grandes contingentes populacionais, está subordinada à grande propriedade e sua

\footnotetext{
${ }^{14}$ As ocupações e a exploração da América Latina em relação aos "descobrimentos", seja na escravidão africana e indígena nas lavouras de cana de açúcar, seja nas minas em México, Peru, etc. são exemplos de tais aceleramentos destrutivos do capitalismo. Mas, Marx também relata tais processos na Inglaterra com a dos camponeses de suas terras para plantar algodão. ${ }^{15}$ Poderíamos pensar as mesmas questões em relação pesca artesanal substituída pela industrial em estudo por MORRONE (2007) e MAICON (2007).
} 
lógica mercantil; já a desvinculação dos meios de produção permanece criando uma forma de subsistência na qual é necessário submeter a venda de sua força de trabalho aos capitalistas.

"El sistema de apropiación capitalista que brota del régimen capitalista de producción, y por tanto la propiedad privada capitalista, es la primera negación de la propiedad individual, basa en el propio trabajo". Sendo assim, evidenciamos a existência de 3 aspectos decorrente dessas citações: o capital, o trabalho e a terra. Sendo estes parte da questão que Marx discute no terceiro tomo do Capital, no capítulo XLVIII, conhecido como Fórmula Trinitaria. Diz que: "Capital-ganancia (beneficio del empresario más interés); tierra-renta del suelo; trabajo-salario: he aquí la fórmula trinitaria que engloba todos los secretos del proceso social de producción" (MARX, 1968, p.754) ${ }^{16}$.

Disso ressalta que, "el capital no es una cosa material, sino una determinada relación social [...]" que "toma cuerpo en una cosa material y le infunde un carácter social especifico"; e que se constituem num "conjunto de los medios de producción monopolizados por una parte de la sociedad, los productos y condiciones de ejercicio de la fuerza de trabajo, substantivados frente a la fuerza del trabajo vivo y a la que este antagonismo personifica como capital". (MARX, 1968, p.754, grifos nossos).

E, de que ao lado dele "aparece la tierra, la naturaleza inorgánica como tal, [...] en toda su rudimentaria y selvática primitividad. El valor es trabajo. La plusvalía o valor de más no puede ser, por tanto, la tierra. La fertilidad absoluta de la tierra quiere decir, sencillamente, que una cantidad de trabajo arroja un determinado producto, condicionado por la fertilidad natural del suelo" ((MARX, 1968 , p. 755 , grifos nossos). E, por fim, aparece o trabalho "como tercer término de la combinación tripartita", o cual "es una abstracción y que, considerado por sí, no existe o que si [...]", que se supõe ser a "actividad productiva del hombre en general, por medio de lo cual se opera el metabolismo con la naturaleza" [...] ((MARX, 1968, p.755). Dito de outro forma,

\footnotetext{
${ }^{16}$ MARX, Carlos. La Fórmula Trinitaria, capítulo XLVIII, El Capital. Crítica de la Economía Política, t. III. ed. México/Buenos Aires: Fundo de Cultura Económica, 1968.
} 
"el trabajo asalariado y la propiedad territorial son, lo mismo que el capital, formas sociales históricamente determinadas, la primera del trabajo, la segunda de la tierra monopolizada, y ambas son, además, formas correspondientes al capital y pertenecientes a la misma formación económica de la sociedad" ((MARX, 1968, p.755) ${ }^{17}$.

Um dos últimos escritos refere-se à Crítica ao Programa de Gotha ${ }^{18}$, que são suas anotações críticas ao texto programa do partido social-democrata alemão. Marx vai citando partes/frases do programa e fazendo ponderações críticas e comentários, e numa determinada parte diz que o trabalho não é a fonte de riqueza, de toda a riqueza, ${ }^{19}$ e diferença valores de uso de valores de troca.

\begin{abstract}
O trabalho não é fonte de toda riqueza. A natureza é a fonte dos valores de uso (os valores de uso são, de fato, a riqueza real!) tanto quanto o trabalho, trabalho que é expressão de uma força natural, a força de trabalho do homem. [...] Só enquanto o homem se coloca, desde o início, como proprietário em relação á natureza, a fonte primeira de todos os meios e objetos de trabalho, e a trata como se ela (a natureza) Ihe pertencesse, é que o seu trabalho se converte em fonte de valores de uso e, portanto, em fonte de riqueza (MARX, 1975, p.10).
\end{abstract}

Portanto, diz Marx, os burgueses têm razões de sobra para atribuir ao trabalho esse poder sobrenatural de criação: precisamente pelo fato de 0 trabalho estar na dependência da natureza se conclui que o homem que possuir apenas a força de trabalho será forçosamente, em qualquer estado [situação] social e de civilização, escravo de outros homens que se tornaram proprietários das condições objetivas do trabalho. Ele não pode trabalhar nem, por conseguinte, viver, a não ser com a autorização destes últimos. (MARX, 2004, p.125-126, In Antunes, 2004)

\footnotetext{
17 Parágrafo citado em Carlos RS Machado, Las implicaciones de los conflictos socioambientales para las ciencias sociales, in: Ética, direito socioambiental e democracia [recurso eletrônico] / org. Aloisio Ruscheinsky, Cleide Calgaro, Thadeu Weber. - Caxias do Sul, RS: Educs, 2018.

${ }^{18}$ Texto escrito por Karl Marx em maio de 1875 - editado a partir de www.insrolux.org/textos/ e publicado in: ANTUNES, Ricardo (org.). A Dialética do Trabalho - escritos de Marx e Engels. São Paulo: Expressão Popular, 2004.

${ }^{19}$ Diz o texto do Programa: "O trabalho é a fonte de toda riqueza e de toda a cultura e, como o trabalho produtivo só é possível na sociedade e pela sociedade, o seu produto pertence integralmente, por igual direito, a todos os membros da sociedade".
} 


\section{O DEBATE DO TRABALHO NO BRASIL ATUAL}

A partir da passagem do trabalho como uma necessidade primeira para sobrevivência, na relação do homem com a natureza, acabou gerou a linguagem, as mudanças corporais, mudanças comportamentais etc. Após 0 desenvolvimento da sociedadese criaram cidades, palácios, represaram-se rios, transformaram-se banhados em áreas agricultáveis... Nesse sentido, Ricardo Antunes destaca: "O trabalho mostra-se, então, como momento fundante de realização do ser social, condição para sua existência; é por isso, ponto de partida para a humanização do ser social" (2005, p.68). Constituindo, também, como um princípio educativo na evolução e humanização do ser social, inclusive em sua potencialidade de emancipação frente à exploração. Conforme Lukács (1981),

[...] a essência do trabalho humano está no fato de que, em primeiro lugar, ele nasce em meio à luta pela existência e, em segundo lugar, todos os seus estádios são produtos da autoatividade do homem. [...] Considerando que nos ocupamos do complexo concreto da sociabilidade como forma de ser, poderse-ia legitimamente perguntar por que, ao tratar deste complexo, colocamos o acento exatamente no trabalho e the atribuímos um lugar tão privilegiado no processo e no salto da gênese do ser social. [...] o trabalho tem, como sua essência ontológica, um claro caráter intermediário: ele é, essencialmente, uma inter-relação entre homem (sociedade) e natureza, tanto inorgânica (utensílio, matéria-prima, objeto do trabalho, etc.) como orgânica, inter-relação que pode até estar situada em pontos determinados da série a que nos referimos, mas antes de mais nada assinala a passagem, no homem que trabalha, do ser meramente biológico ao ser social (p. 2 e 3).

No capitalismo, os trabalhadoresvivem na medida em que encontram trabalho, ou possuam outros meios de subsistência, mas, em ambos os casos, tendem a se tornar mercadorias e estão sujeitos a qualquer vicissitude da concorrência comercial, ou seja, a todas as flutuações do mercado. "O desenvolvimento da burguesia, isto é, do capital, corresponde, na mesma proporção, ao desenvolvimento do proletariado, da classe dos operários modernos [...]." (MARX; ENGELS, 2002, p. 35).

Os seres humanos produzem para satisfazer suas necessidades através de sua relação de transformação da natureza, na produção de meios necessários de sua vida material, ligam o mundo material e o mundo social, 
sendo isso possível apenas pelo trabalho (SOUZA, 2008). E, conforme Marx (1985), o trabalho é "[ ...] uma condição de existência do homem, independente de todas as formas de sociedade, eterna necessidade natural de mediação do metabolismo entre homem e natureza e, portanto, da vida humana" (p. 50).

No entanto, tal mediação avança para uma ruptura devido àsuperexploração da natureza e de seus recursos, em benefício de poucos e com vistas ao desenvolvimento sem fim do consumismo, considerando a obsolescência programada ${ }^{20}$ dos produtos colocados no mercado. Do ponto de vista social, no capitalismo não é possível existir uma igualdade real de direitos (sociais, de desenvolvimento humano, etc.), pois é um sistema que se baseia, fundamentalmente, na extração da mais valia e maximização dos lucros dos detentores dos meios de produção, bem como na própria relação desigual que trabalhador enfrenta com seu empregador.

O trabalhador se torna mais pobre quanto mais riqueza produz. Gerando, portanto, uma valorização do mundo das "coisas" em detrimento da desvalorização do mundo dos homens. Contudo, a consciência desse processo de estranhamento não retira as condições estranhas desse trabalho, porém, não coloca esse processo no plano do fatalismo. Assim, a partir do momento da consciência surge a militância dos trabalhadores.

A primeira Revolução Industrial, na Grã-Bretanha, caracteriza-se como uma das primeiras geradoras de reações da classe trabalhadora à exploração capitalista. A resistência à introdução das máquinas fabris gerou uma luta árdua, pois as máquinas eliminaram postos de trabalho e obrigavam os trabalhadores a um ritmo mais intenso de labor. Contudo, não houve como brecar o avanço tecnológico (SOUZA, 2003). Com a necessidade de regulamentação do trabalho nas fábricas (tanto pelos interesses dos empresários capitalistas de eliminar a concorrência de fábricas menores,

${ }^{20}$ Guillermo Arenas, La obsolescencia programada nos obliga a entrar en un ciclo sin fin de consumo y desperdicio, pero se plantean otras vías para salir del ciclo comprar-tirar-comprar, in. RETINA, EI País,

17 outubro de 2018. 
quanto pela necessidade de se repensar as condições de trabalho dos trabalhadores), surge a lei fabril, elaborada em 1872.

Após a II Guerra Mundial (1973) - na Europa e na América do Norte - a crise do pós-guerra, a baixa taxa de crescimento e as altas taxas de inflação proporcionaram terreno para o surgimento do neoliberalismo, que provocou mudanças consideráveis na relação do capital e trabalho, as desigualdades e a produção. Caracteriza-se por uma reação teórica e política contra o Estado intervencionista e de bem-estar social. Fundado na Suíça, por uma espécie de uma franco-maçonaria, tinha como propósito combater o Keynesianismo e o solidarismo para a preparação para um novo capitalismo - mais duro e menos regulado. Um de seus principais argumentos era de que a desigualdade era um valor positivo para o capital (ANDERSON, 1995). Marx e Engels, em meados de 1848, já identificavam o processo permanente de estratégias da burguesia para a abstração do sentido do trabalho e para a garantia de mais acumulação de capital:

A burguesia não pode existir sem revolucionar permanentemente os instrumentos de produção; portanto, as relações de produção; e assim, o conjunto das relações sociais. [...] $\bigcirc$ revolucionamento permanente da produção, 0 abalo contínuo de todas as categorias sociais, a insegurança e a agitação sempiternas distinguem a época burguesa de todas as precedentes. [...] Tudo o que era estável e sólido desmancha no ar; tudo o que era sagrado é profanado, e os homens são obrigados a encarar com os olhos desiludidos seu lugar no mundo e suas relações recíprocas (MARX; ENGELS, 2002, p. 28).

A vivência de uma crise salarial e a mudança das relações do mercado e de produção, a partir da Terceira Revolução Industrial, cria campo para o processo de ampliação de novas alternativas e formas de organização popular, muitas relacionadas ao movimento operário, para sustento desse contingente trabalhador desempregado; mas, também, como um local de legitimação dos saberes dessestrabalhador.

Atualmente, a classe trabalhadora complexificou-se, no sentido de uma maior heterogeneização e fragmentação como classe. Isso porque, cada vez mais o trabalho problematiza com todas as dimensões da vida. Ou seja, tornase intrínseco ao homem. 


\section{A CLASSE TRABALHADORA NO BRASIL - DA OLIGARQUIA AO CAPITALISMO}

A análise das leis que regulam as relações de trabalho passa, impreterivelmente, pela compreensão do contexto histórico e social em que se implementam. Por isso, buscaremos retratar o desenvolvimento do capitalismo no Brasil tendo a obra de Florestan Fernandes como referência.

Florestan Fernandes um dos grandes intelectuais brasileiros, preocupouse em realizar uma interpretação autêntica da realidade nacional, e para tanto, critica modelos ideais nas ciências humanas, ou importados, buscando desenvolver evidências a partir de pesquisas de profundidade empírica, articulando-a aos processos históricos-sociais.

Esse autor passa pela análise da organização das sociedades indígenas e pela constituição do escravismo no país chegando à análise do desenvolvimento do capitalismo, no seu livroA Revolução Burguesa no Brasil, de 1975. Dentre diversas contribuições, ressalta-se o entendimento de que o processo de implementação de um projeto burguês de dominação e desenvolvimento ocorre de forma distinta do que se verificou na Europa. Nesse sentido, afirma:

\footnotetext{
Ao contrário de outras burguesias, que forjaram instituições próprias de poder especificamente social e só usaram o Estado para arranjos mais complicados e específicos, a nossa burguesia converge para o Estado e faz sua unificação no plano político, antes de converter a dominação socioeconômica no que Weber entendia como "poder político indireto. (FERNANDES, 2005, p. 240)
}

Sua debilidade no cenário político e econômico decorre da forma histórica com que a economia brasileira se relacionou com o mundo, ocupando um espaço de exportador de commodities, seja na forma de minérios ou produtos agrícolas. Assim, a burguesia nascente, ligada particularmente ao comércio, não pôde confrontar o poder político consolidado da oligarquia, a qual se encontrava intimamente ligada à escravidão. Assim, a dita burguesia, sem força política para o enfrentamento da oligarquia, num mercado marcado pela escravidão, numa sociedade em constante estado de exclusão e de revolta, articula-se a oligarquia para a manutenção da estabilidade social, 
prioritária aos interesses do nascente capitalismo. Portanto, opta-se pela acomodação de interesses em um processo de transformação econômica e social gradual, segura aos setores dominantes. Os discursos dos liberais não encontram conexão com a realidade, justamente pela base sobre a qual seu poder se efetivou.

As representações ideais da burguesia valiam para ela própria e definiam um modo de ser que se esgotava dentro de um circuito fechado. Mais que uma compensação e que uma consciência falsa, eram um adorno, um objeto de ostentação, um símbolo de modernidade e de civilização. Quando outros grupos se puseram em condições de cobrar essa identificação simbólica, ela se desvaneceu. (FERNANDES, 2005, p. 242)

Essa percepção se confirma na história recente do Brasil, em que os espaços de sociabilidade e de consumo dos setores médios, associados à ideologia dominante, passaram a ser ocupados por sujeitos que ficavam até então às margens. Shoppings Centers, aeroportos, mercados, clubes e outros espaços passaram a ser ocupados de forma mais democrática nas últimas décadas, principalmente a partir dos governos do Partido dos Trabalhadores, que inicia em 2003 e se encerra em 2016. Frente a isso, diversas manifestações de descontentamento foram expressas por aqueles que se diziam defensores do liberalismo, expressando a prevalência de sua constituição de classe marcadamente autoritária e excludente. Disso nasce uma tendência própria de liberalismo-conservador, tão em voga atualmente. As ideias fora de lugar de Roberto Schwarz, que analisa parte do discurso liberal em uma sociedade de base escravista, explicam esse espaço no discurso político ${ }^{21}$.

Os elementos acima apresentados marcam a forma como foi efetivada a dominação burguesa e como se desenvolve o capitalismo no Brasil, e que ainda persistem. Nesse sentido, ressalta-se a conclusão desenvolvida por Florestan:

No entanto, a burguesia atinge sua maturidade e, ao mesmo tempo, sua plenitude de poder sob a irrupção do capitalismo monopolista, mantidas e agravadas as demais condições, que tornaram a sociedade brasileira potencialmente explosiva, com

\footnotetext{
${ }^{21}$ Disponível em: <https://diplomatique.org.br/liberal-conservadorismo-a-brasileira/>. Acesso em: 01 nov. 2018.
} 
o recrudescimento inevitável da dominação externa, da desigualdade social e do subdesenvolvimento. Em consequência, o caráter autocrático e opressivo da dominação burguesa apurou-se e intensificou-se (processo que, sem dúvida, continuará, mesmo que encontre formas eficientes de dissimulação, como sucedeu com a dominação senhorial no Império). Não só porque ainda não existe outra força social, politicamente organizada, capaz de limitá-la ou de detê-la. Mas também porque ela não tem como conciliar o modelo neoimperialista de desenvolvimento capitalista, que se impôs de fora para dentro, com os velhos ideais de Revolução Burguesa nacional-democrática. (2005, p. 258)

Esse trecho reforça a tese de que a burguesia brasileira atinge 0 máximo de seu poder através da conciliação com setores oligárquicos, ainda dominantes, que possuíam estratégias de dominação próprias, marcadamente autoritárias Apenas depois se buscou construir sua hegemonia através da conciliação na manutenção da estratificação social e da exploração do trabalho e da natureza de forma mais ampla e possível, mesmo que isso vá contra as abstrações teóricas liberais.

O fim dos 21 anos de domínio direto militar, iniciado em 1964, não alterou consideravelmente a constituição sócio-econômica do Brasil, pois o próprio processo de transição foi de uma abertura lenta, gradual e segura, conforme projeto encabeçado por Ernesto Geisel em $1974^{22}$. Não há evidência significativa de alteração na composição social, tanto mais porque a desigualdade no país apenas se intensificou ${ }^{23}$ e porque os grupos que tomaram o poder em 1964 saíram fortalecidos desse período. A ditadura serviu para a implementação de um projeto econômico atrelado, principalmente, aos interesses do neoliberalismo, como evidenciou pioneiramente René Dreifuss ${ }^{24}$, em 1981; e que, agora Bolsonaro e Paulo Guedes querem intensificar. Assim, o Brasil da redemocratização é um país de maior concentração de riquezas e mais atrelado aos interesses do capitalismo mundial e de uma burguesia articulada a uma oligarquia latifundiária e de banqueiros especuladores dos recursos naturais e do trabalho.

22 Disponível em: <https://acervo.oglobo.globo.com/em-destaque/ernesto-geisel-pai-dadistensao-lenta-gradual-segura-da-ditadura-militar-20071730>. Acesso em: 01 nov. 2018.

Disponível em: <http://professor.ufop.br/alexandre/classes/teoria-daconstitui\%C3\%A7\%C3\%A30 -dir521/materials/ditadura-militar-aumento-da-desigualdade>. Acesso em: 01 nov. 2018.

${ }^{24}$ DREIFUSS, René. 1964: A conquista do Estado (Ação política, poder e golpe de classe). Petrópolis: Vozes, 1981. 
Essa união constitui uma das principais características da burguesia brasileira, que se mostrou autoritária em todos os momentos em que se viu consideravelmente contestada em seus espaços de poder. Isso marca a contrarrevolução defensiva mantida pelos setores dominantes brasileiros, a qual pode ser percebida ainda nos dias de hoje. De inovador, há o surgimento de uma nova organização política, o Partido dos Trabalhadores (PT), em 1980, tendo sido articulado na oposição à ditadura civil-militar por setores populares da igreja católica, intelectuais, sindicatos e grupos de esquerda que estavam clandestinos. Desde seu surgimento, passa por transformações na radicalidade de seu discurso, tendendo a um tom menos intenso com a passagem das eleições, a assunção de governos e com a crise dos países socialistas, apesar do PT ter críticas a tais regimes. As eleições presidenciais de 2002 marcam significativamente essa transformação, onde a "Carta ao Povo Brasileiro" representa tal inflexão visando a aliança com parte das classes dominantes até 2013, com a ruptura em 2016 com a destituição de Dilma Rousseff. ${ }^{25}$

A análise realizada pelo historiador Perry Anderson sobre os governos do PT destaca esse caráter conciliador, o que os afasta dos governos populistas de Vargas, no Brasil, e Perón, na Argentina:

O exercício de poder de Lula não envolveu nada disso. Sua ascensão foi baseada em um movimento sindical e um partido político muito mais moderno e democrático do que qualquer coisa que Vargas ou Perón jamais haviam imaginado. Mas, à época em que ele ganhou a presidência, na sua quarta tentativa, o PT tinha sido reduzido em grande parte a uma máquina eleitoral. Uma vez no poder, Lula não mobilizou e nem mesmo incorporou o eleitorado que o aclamara. Nenhuma conformação estrutural nova deu forma à vida popular. A marca de seu governo foi, pelo contrário, a da desmobilização. Os sindicatos organizavam mais de $30 \%$ da força de trabalho formal na década de 1980, quando Lula fez seu nome como o líder sindical mais talentoso. Hoje em dia, eles representam $17 \%$. O declínio precedia seu período no cargo, mas não foi alterado por ele. Até mesmo a contribuição sindical, que remonta à legislação de cunho fascista do Estado Novo, cuja dedução e distribuição de cotas por parte do Estado foi vista pelo PT durante muito tempo, e com razão, como um mecanismo para destruir os alicerces do ativismo sindical, e cuja abolição foi uma das principais exigências do início dos anos 1980, foi deixada intocada. (ANDERSON, 2011, p. 33)

${ }^{25}$ Para saber mais, acessar: <http://www.pt.org.br/ha-16-anos-lula-lancava-a-carta-ao-povobrasileiro/>. Acesso em: 01 nov. 2018. 
Salienta que há certo continuísmo no que tange à hegemonia da burguesia nacional. O PT consegue implementar significativos projetos para a transformação social, profundas em relação à redução da miséria e da fome, no enfrentamento do racismo e do acesso ao ensino superior. Contudo, não atua sobre o centro do poder econômico, inclusive ressalta a acumulação de riquezas $^{26}$. O PT não provoca efetiva confrontação aos setores historicamente dominantes. Dessa forma, entende-se que as transformações implementadas foram possíveis por conta da expansão das margens da conciliação, que foram aceitas devido à manutenção da conjuntura em que "os lucros nunca foram tão altos".

Ocorre que o apoio desses setores e a conciliação começam a ruir a partir da alteração das condições que permitiram o crescimento econômico dos anos anteriores. Agrava esse quadro a crise política instaurada a partir das eleições de 2014, que iniciou com a contestação dos resultados das eleições e culminou com a deposição da presidente Dilma Rousseff, em agosto de 2016. Com ela, cresce a instabilidade social, que sempre possui um alto potencial disruptivo em um país marcado pela desigualdade.

A conciliação é encerrada assim que a conjuntura favorável se verifica limitada, de modo que o modelo de desenvolvimento econômico e social propostos pelos governos do PT é preterido frente às formas tradicionais de se fazer política, em que o corte de direitos e redução do Estado são fundamentais. Assim, entende-se que as reformas implementadas a partir de 2016 estão conjugadas com a reafirmação dos espaços e grupos tradicionalmente dominantes. Frente a esse cenário, a tese construída por Florestan Fernandes para explicar o desenvolvimento do capitalismo no Brasil e a constituição de sua burguesia acaba por se reafirmar, colocando em perspectiva quais interesses estão em disputa.

\section{CONTEXTO POLÍTICO E SOCIAL BRASILEIRO - QUE REFORMAS TRABALHISTAS SÃO ESSAS?}

\footnotetext{
${ }^{26}$ Para saber mais, acessar: <https://brasil.elpais.com/brasil/2018/09/17/economia/1537197185 613692.html>. Acesso em: 01 nov. 2018.
} 
O pacto social, realizado em 1988, que culminou na "Constituição Cidadã", tratou-se de um pacto de comprometimento pelos acordos políticos firmados para a garantia de direitos sociais, assim como a garantia do Estado de bem estar social. Todavia, desde a criação desse pacto, que seria 0 garantidor de direitos à população, não houve uma reavaliação do sistema capitalista de produção. Percebemos que houve sim um acordo de "convivência". Isso porque, desde a redemocratização, evidencia-se que o Estado brasileiro prioriza o sistema capitalista de produção ao invés de garantir, atualizar e manter os direitos da classe trabalhadora. Ou seja, as reformas de precarização do trabalho, funcionam para o enfraquecimento dos trabalhadores como atores políticos, aumentando desigualdades e vulnerabilidades, além de negligenciar os direitos sociais às classes populares. Essas reformas de cunho neoliberal vêm sendo implementadas, de forma contundente, impactante no Brasil, na América Latina e no mundo.

No que tange à relação ao Estado no neoliberalismo, percebemos que esse só é mínimo quanto à garantia de direitos sociais para a população; sendo o Estado total quanto aos respaldos legais e financeiros aos empresários e investidores - principalmente em situações de crise financeira. Evidencia-se, portanto, a existência da tendência do Estado brasileiro não priorizar os interesses dos trabalhadores.

A política de governo desde Lula, e mantendo-se e acentuando-se no governo de Dilma, trava parcialmente o neoliberalismo; mas, ao mesmo tempo, ao invés de unir-se com os movimentos sociais, une-se a partidos políticos com pequenas minorias influentes, para a implementação de um modelo neodesenvolvimentista. Tentando fazer essa mediação entre burguesia e proletariado, o governo acabou instrumentalizando parte do movimento social, que se viu em diversos momentos defendendo políticas que não eram totalmente condizentes com seus reais interesses. Isso ocasionou instabilidade nos movimentos sociais, que sofrem, também, com as trocas de ministérios, alterações de verbas, cortes de recursos. E acaba por não satisfazer totalmente os interesses dos empresários, na medida que esses se vêem pressionados por maximização dos lucros, contrastando com um governo que 
aumentou o investimento em políticas de assistência social e em programas de complementação de renda e alimentação.

A Reforma Trabalhista (Lei no 13.467 de 2017), a Lei das Terceirizações (Lei 13.429 de 2017), a Emenda Constitucional 95 (EC 95/2016), que congela os gastos públicos por 20 anos, e a tentativa de Reforma da Previdência são as medidas em processo na sociedade brasileira, colocando em vigor uma agenda neoliberal profunda.

O ideário da política econômica dos governantes que assumiram o poder depois do impedimento da ex-presidente Dilma Rousseff fundamenta-se na crença de que 0 crescimento econômico é papel essencialmente da iniciativa privada, em particular dos investimentos, os quais, por sua vez, dependem do custo de produção e da confiança dos empresários na solidez das finanças públicas, nas garantias legais e contratuais, na estabilidade da moeda e, no mínimo, na manutenção da tributação, senão em sua redução. Esse ideário se desdobrou nas medidas concretas adotadas pelo governo: privatização de empresas públicas ou de partes delas; desmonte dos direitos trabalhistas e sindicais; liberação da terceirização irrestrita, inclusive no setor público; imposição de congelamento real do valor investido nas políticas públicas por 20 anos; redução dos fundos do BNDES e aumento do custo dos empréstimos; revisão do modelo de exploração do petróleo do pré-sal, com liberação para empresas privadas e redução dos requisitos de conteúdo nacional; vinculação dos preços dos produtos da Petrobras às cotações Internacionais; entre outras ações ${ }^{27}$.

Contudo, é sabido que essas reformas não são algo do governo Temer, essas alterações no Sistema Nacional de relações de trabalho são realizadas desde a década de 1990 (Lei 8.949/94, MP 794/94, Lei 9.300/96, Lei 9.601/98). Foram cerca de 200 alterações realizadas na CLT, e todas essas sem ampla discussão social, seja na forma de plebiscito ou referendo. Trata-se, portanto, de um processo de adequação às legal transformações sociais e de precarização do trabalho que têm longa história no país. nov. 2018. 
Em todo caso, após a implementação da Reforma Trabalhista ${ }^{28}$, há uma alteração sem precedentes nos sentidos da CLT. A seguir, apresentamos mudanças que mais reduzem os direitos dos trabalhadores ${ }^{29}$ :

- Tempo na empresa: a CLT considerava como serviço efetivo o período em que o empregado estava à disposição do empregador, aguardando ou executando ordens. Agora, descanso, estudo, alimentação, interação entre colegas, higiene pessoal e troca de uniforme não são considerados como tempo de trabalho dentro da jornada de trabalho da empresa.

- Descanso: quando a jornada era padrão de 8 horas diárias havia 0 direito a no mínimo uma hora e a no máximo duas horas de intervalo para repouso ou alimentação. Com a nova regra o intervalo pode ser negociado, desde que haja pelo menos 30 minutos de descanso. Caso o empregador não conceda esse tempo deverá pagar indenização de 50\% do valor da hora normal de trabalho apenas sobre o tempo não concedido, ao invés de todo o tempo de intervalo devido.

- Plano de cargos e salários: antes, o plano de cargos e salários precisava de homologação no Ministério do Trabalho e constar do contrato de trabalho. Agora, o plano de carreira é negociado entre patrões e trabalhadores sem necessidade de homologação nem registro em contrato, podendo ser mudado a qualquer momento.

- Transporte (in itinere): quando a localidade da empresa era de difícil acesso ou impossibilitado uso de transporte público era remunerado o tempo de deslocamento. Na nova regra o tempo de ida até o local de trabalho e o tempo de retorno, por qualquer meio de transporte, não será computado na jornada de trabalho.

- Trabalho intermitente (por período): na antiga legislação essa modalidade de contratação não era possível. Atualmente, o trabalhador poderá ser pago por período trabalhado, recebendo pelas horas ou pela diária. Há o direito a férias, Fundo de Garantia do Tempo de Serviço (FGTS), previdência e $13^{\circ}$ salário proporcionais. No contrato deverá estar estabelecido o valor da hora de trabalho, que não pode ser inferior ao valor do salário mínimo por hora ou à remuneração dos demais empregados que exerçam a mesma função. O empregado deve ser convocado com, no mínimo, três dias corridos de antecedência. No período de inatividade, pode prestar serviços a outros contratantes.

28 Lei completa disponível em: <ttp://www.planalto.gov.br/ccivil 03/ ato20152018/2017/lei/L13467.htm>. Acesso em: 01 nov. 2018.

${ }_{29}$ Disponível em: <https://g1.globo.com/economia/noticia/reforma-trabalhista-e-aprovada-nosenado- confira-o-que-muda-na-lei.ghtml>. Acesso em: 01 nov. 2018. 
- Trabalho remoto (home office): na antiga legislação essa modalidade de contratação não era possível. Na nova legislação, tudo o que o trabalhador usar em casa deve ser formalizado com o patrão via contrato, como equipamentos e gastos com energia e internet, e o controle do trabalho será feito por tarefa.

- Negociação: as convenções e os acordos coletivos podiam estabelecer condições de trabalho diferentes das previstas na legislação apenas se conferissem ao trabalhador um patamar superior ao que estivesse previsto na lei. Atualmente, esses acordos e convenções podem prevalecer sobre a legislação. Assim, os sindicatos e as empresas podem negociar condições de trabalho diferentes das previstas em lei, mas não necessariamente num patamar melhor para os trabalhadores ${ }^{30}$. Ainda, permitiu-se, nesses limites, a negociação com empregados com instrução de nível superior e salário mensal igual ou superior a duas vezes o limite máximo dos benefícios do INSS (isto é, $R \$ 11.062,62 \mathrm{em}$ 2017), prevalecerão sobre o acordo coletivo.

- Prazo de validade das normas coletivas: integravam os contratos individuais de trabalho e só poderiam ser modificados ou suprimidos por novas negociações coletivas. Passado o período de vigência, permaneciam valendo até que fossem feitos novos acordos ou convenções coletivas. Agora, o que for negociado não precisará ser incorporado ao contrato de trabalho. Os sindicatos e as empresas poderão dispor livremente sobre os prazos de validade dos acordos e convenções coletivas, bem como sobre a manutenção ou não dos direitos ali previstos quando expirados os períodos de vigência. $E$, em caso de expiração da validade, novas negociações terão de ser feitas.

- Representação: era assegurada a eleição de um representante dos trabalhadores nas empresas com mais de 200 empregados, mas não havia regulamentação sobre isso. Esse delegado sindical tinha todos os direitos de um trabalhador comum e estabilidade de dois anos. Na nova regra os trabalhadores poderão escolher 3 funcionários que os representarão em empresas com no mínimo 200 funcionários na negociação com os patrões. Os representantes não precisam ser sindicalizados. Os sindicatos continuarão atuando apenas nos acordos e nas convenções coletivas.

- Demissão: quando o trabalhador pedia demissão ou era demitido por justa causa, não tinha direito à multa de $40 \%$ sobre o saldo do FGTS nem à retirada do fundo. Em relação ao aviso prévio, a empresa poderia avisar o trabalhador sobre a demissão com 30 dias de antecedência ou

\footnotetext{
${ }^{30} \mathrm{Em}$ negociações sobre redução de salários ou de jornada, deverá haver cláusula prevendo a proteção dos empregados contra demissão durante o prazo de vigência do acordo. Esses acordos não precisarão prever contrapartidas para um item negociado.
} 
pagar o salário referente ao mês sem que o funcionário precise trabalhar. Agora o contrato de trabalho poderá ser extinto de comum acordo, com pagamento de metade do aviso prévio e metade da multa de $40 \%$ sobre o saldo do FGTS. O empregado poderá ainda movimentar até $80 \%$ do valor depositado pela empresa na conta do FGTS, mas não terá direito ao seguro-desemprego.

- Danos morais: o valor em ações envolvendo danos morais eram estipulados pelos juízes que julgavam o processo. Com a reforma, a proposta impõe limitações ao valor a ser pleiteado pelo trabalhador, estabelecendo um teto para alguns pedidos de indenização. Ofensas graves cometidas por empregadores devem ser de no máximo 50 vezes o último salário contratual do ofendido.

- Contribuição sindical: anteriormente a contribuição era obrigatória. O pagamento era feito uma vez ao ano, por meio do desconto equivalente a um dia de salário do trabalhador. Já, com a atualização, a contribuição sindical é opcional.

- Terceirização: presidente Michel Temer sancionou o projeto de lei que permite a terceirização para atividades-fim. Portanto, com a nova legislação em vigor existia uma quarentena de 18 meses que impedia que a empresa demitisse o trabalhador efetivo para recontratá-lo como terceirizado. Prevê, ainda, que o terceirizado deve ter as mesmas condições de trabalho dos efetivos, como atendimento em ambulatório, alimentação, segurança, transporte, capacitação e qualidade de equipamentos.

- Gravidez: as mulheres grávidas ou lactantes eram proibidas de trabalhar em lugares com condições insalubres. Além disso, não havia limite de tempo para avisar a empresa sobre a gravidez. Com a reforma torna-se permitido o trabalho de mulheres grávidas em ambientes considerados insalubres, desde que a empresa apresente atestado médico que garanta não haver riscos ao bebê nem à mãe. Mulheres que forem demitidas têm até 30 dias para informar a empresa sobre a gravidez.

- Banco de horas: Além do limite de 10 horas diárias, o excesso de horas em um dia de trabalho poderia ser compensado em outro dia, desde que não excedesse, no período máximo de um ano, à soma das jornadas semanais de trabalho previstas. Com a nova regra o banco de horas pode ser pactuado por acordo individual escrito, desde que a compensação se realize no mesmo mês.

- Rescisão contratual: A homologação da rescisão contratual deveria ser realizada no sindicato da categoria. Agora, a homologação da rescisão do contrato de trabalho pode ser feita na empresa, na presença dos advogados do empregador e do funcionário - que pode ter assistência do sindicato. 
- Ações na Justiça: Os honorários referentes a perícias eram pagos pela União e quem entrasse com a ação não tinha nenhum custo. A Reforma instituiu que o trabalhador é obrigado a comparecer nas audiências da Justiça do Trabalho e, caso perca a ação, arcar com as custas do processo. Para os chamados honorários de sucumbência, devidos aos advogados da parte vencedora, quem perder a causa terá de pagar entre $5 \%$ e $15 \%$ do valor da sentença ${ }^{31}$.

Das alterações aqui apresentadas, em relação à jornada de trabalho há uma flexibilização e retrocesso em relação às horas trabalhadas por dia, dado que na prática não é garantido que o trabalhador consiga negociar esse tempo devido à demanda de trabalho. Além disso, a diminuição do tempo de descanso acarreta um maior desgaste do trabalhador, devido a isso não garantir que esse saia mais cedo do trabalho. Menos tempo de descanso é maior desgaste físico e mental da categoria.

A regularização do trabalho intermitente é um passo para a negligência para com os trabalhadores, visto que a garantia de trabalho não existe. Desestabiliza o princípio da estabilidade contratual. Deixa os trabalhadores mais à mercê do patrão, propiciando a necessidade de negociação e acordos, possivelmente não justos em relação à garantia de direitos e saúde dos trabalhadores, por terem que procurar mais de um emprego intermitente devido a ausência de garantia de solicitação de trabalho.

A possibilidade do trabalho remoto, nos traz a certeza do avanço tecnológico, ou seja, a tecnologia alterando a forma de realização do trabalho pelos trabalhades e abrindo possibilidade de um novo tipo de exploração. Sem regras, sem limites, ou seja, uma onipresença de realização de demandas por via online. Trabalhar em casa não significa apenas ter mais conforto, pode significar uma exploração desenfreada da força de trabalho do empregado,

\footnotetext{
${ }^{31} \mathrm{O}$ trabalhador que tiver acesso à Justiça gratuita também estará sujeito ao pagamento de honorários de perícias se tiver obtido créditos em outros processos capazes de suportar a despesa. Caso contrário, a União arcará com os custos. Da mesma forma, terá de pagar os honorários da parte vencedora em caso de perda da ação. Caso o empregado assine a rescisão contratual, fica impedido de questioná-la posteriormente na Justiça trabalhista. Além disso, fica limitado a 8 anos o prazo para andamento das ações. Se até lá a ação não tiver sido julgada ou concluída, o processo será extinto.
} 
pois é atenuado o controle da jornada. Além disso, às custas do trabalhador reduz os gastos operacionais do empregador. Possui impacto, também, a atomização dos empregados, o que dificulta a formação de consciência de classe.

Sobre as alterações relativas à negociação, representação, acordos coletivos e contribuição ao sindicato demonstram claramente a ideia de colocar o trabalhador no mesmo patamar negocial do patrão, dando a falsa ideia de que estes ocupam o mesmo nível de poder no local de trabalho. A Reforma Trabalhista aposta no incremento da autonomia do trabalhador frente ao empregador, contudo, essa ocorre na forma de liberalização dos direitos. A CLT acaba resguardando na forma da lei apenas os elementos contidos no artigo $7^{\circ}$ da Constituição Federal, de modo que somente esses não podem ser negociados pelos sindicatos, e certos empregados, com os patrões.

Retirar a contribuição sindical e a liberação da atuação sindical na fiscalização da demissão e dos acordos entre trabalhadores e patrão notoriamente significa uma possibilidade de negligenciamento de direitos sem que o trabalhador tenha conhecimento disso. Não estar a par de seus direitos, e não ter tempo para isso, visto às alterações na jornada de trabalho, acaba desmobilizando e tornando o trabalhador mais vulnerável e suscetível aos abusos de poder por parte do empregador.

Em relação aos direitos das mulheres trabalhadoras, relativo à possibilidade de trabalho em lugares com condições insalubres é um retrocesso gritante, inimaginável se comparado com o cenário internacional. 0 Brasil estava passando por transformações construtivas nesse campo, vindo de uma crescente de garantia dos direitos das mulheres e mães (parto humanizado pelo SUS, horário de trabalho diferenciado para amamentação, etc.) e, também, em relação aos pais (aumento dos dias de licença paternidade, alteração dos papéis de cuidado com as crianças - pais do lar, etc.). Possibilitar às mulheres grávidas que trabalhem nesses locais é mais uma vez legitimar a misoginia existente em nossa sociedade. 
Ao retroceder nos direitos dos trabalhadores, nessa onda neoliberal, talvez possamos estar vivendo um processo de alteração da organização societal, assim como trazido por Marx (2013), como já exposto anteriormente. O aguçamento das contradições e antagonismo da forma capitalista de produção, acabam favorecendo as condições materiais e as combinações sociais do processo de produção. Levando, ao mesmo tempo, o amadurecimento de elementos que formam uma nova sociedade com os elementos destruidores da sociedade antiga, que já deveria ter sido superada.

Colocar o trabalhador como se estivesse em mesmo patamar do patrão para negociar seus acordos e direitos contratuais é legitimar a lógica do pequeno empresário que, desde a década de 80 , com o início da globalização e a enxurrada do norte-americanismo, tem essa lógica imposta em nossa sociedade. "Faça você mesmo", "monte seu próprio negócio", "você é responsável pelo seu crescimento" ou seja, a política do mérito. Mérito que é cego para perceber quais são as reais relações de poder que existem, seja na relação de trabalho ou na composição histórica de nossa sociedade. Pelas mídias, o discurso do patrão foi introjetada à hegemonia que permeia a consciência popular, sendo que nossa população não se dá conta que o ponto de partida não é igual para todos. Criando, assim, a cultura da meritocracia, que apenas consolida e justifica as desigualdades que grassam na sociedade brasileira.

Bem se sabe que estar mais tempo no trabalho não é garantia de maior produção. O trabalhador não consegue ser produtivo no total de horas de trabalho, ampliar a jornada e diminuir o tempo de descanso só fará com que o desgaste dos trabalhadores seja duplicado. Impedindo que haja tempo para o lazer, para a educação/formação, para viver. Marx já trazia a importância do lazer e da espiritualidade para o trabalhador. Assim, pode-se entender que a liberalização das jornadas e intensificação do tempo de trabalho significa maior esgotamento e isolamento do trabalhador, que não se vê representado e não consegue se educar para se representar. Dessa forma, trata-se de mais uma das medidas para intensificar o controle através da alienação do trabalhador. 
Esses retrocessos só trazem a certeza de que a querem desmobilizar e tornar vulnerável o trabalhador brasileiro.

\section{ALGUNS APONTAMENTOS - O NOVO GOVERNO EM CURSO}

Com o resultado das eleições, as perspectivas para o Brasil no que tange aos direitos dos trabalhadores não são animadoras. O país elegeu 0 candidato que indicava que o trabalhador teria que escolher entre a existência de direitos trabalhistas ou de empregos ${ }^{32}$. Além disso, é defensor de uma carteira de trabalho "verde e amarela", que permita redução dos direitos nos limites do que seria acertado em negociação individual ${ }^{33}$. Esta proposta seria voltada, inicialmente, para pessoas entre 20 e 25 anos, a fim de facilitar 0 acesso ao mercado de trabalho pelos jovens, contudo, criaria duas categorias de trabalhadores e pressionaria os salários dos demais trabalhadores ainda mais para baixo.

Para além da alteração das contratações sem o regime da CLT, com salário fixo e postos formais, a substituição por contratações atípicas e precárias tende à crescente flexibilização do mercado de trabalho. Impondo ao trabalhador a imprevisibilidade de salário (sem renda fixa), imprevisibilidade de contratação e maior subjugação ao empregador. Além disso há a potencial diminuição do poder de compra do salário, situação que restringe a participação na economia do país, precarizando a qualidade de vida e o acesso aos bens de consumo básicos.

Os trabalhadores que mais sofrem com essa precarização são os dos setores já precarizados anteriormente (assistente de vendas, teleatendimento, domésticas, auxiliares de serviços gerais, etc.), esses que já vivem grande rotatividade de emprego e menores salários. Ou seja, já eram historicamente vulneráveis antes da reforma, tendo sua situação agravada.

\footnotetext{
$32 \quad$ Para mais:

$<$ https://www.infomoney.com.br/mercados/politica/noticia/7589379/bolsonaro-diz-no-in-quetrabalhador-tera-de-escolher-entre-direitos-e-emprego > Acesso em 02 de novembro de 2018 ${ }_{33}$ Para saber mais: <https://oglobo.globo.com/economia/conheca-as-propostas-de-bolsonaropara-emprego-de-jovens-23195669>. Acesso em 01 nov. 2018.
} 
A tendência é o aumento do número de desempregados e da precarização dos trabalhadores visto a agenda governamental de Jair Bolsonaro e a instabilidade política-financeira que atravessa o Brasil ${ }^{34}$. Além disso, a reforma trabalhista só reafirma essa instabilidade de emprego para os trabalhadores, não tendo apresentado qualquer resultado significativamente animador desde que foi implementada. Além de ter mantido as taxas de desemprego em patamares recordes, a reforma gerou insegurança jurídica por sua redação e por possuir conteúdo potencialmente inconstitucional ${ }^{35}$.

Ainda, figura como elemento fundamental na agenda do próximo governo a reforma da previdência, causando impactos diretos aos trabalhadores. Essa reforma, como foi apresentada pelo governo Temer e pela equipe do candidato eleito, tende à manutenção do sistema tributário regressivo, que prejudica diretamente o trabalhador de menor renda. Existe, ainda, a possibilidade de se criar uma taxa única sobre a renda, rebaixando ainda mais a posição dos trabalhadores mais precários, grupo que somente vem crescendo ${ }^{36}$. Além disso, não há discussão séria sobre setores que são historicamente privilegiados e oneram de forma excessiva a previdência, com destaque para os militares. Ocorre que a reforma da previdência tem sido solicitada pelo presidente eleito, Jair Bolsonaro, para ser aprovada ainda antes de sua posse.

\section{CONSIDERAÇÕES}

Mostramos, ao início, que a trabalho é uma ação de mediação do trabalhador com a natureza visando criar bens e produtos, coisas e alimentos, ou seja, decorre da transformação da natureza pela ação do homem. Em relação ao desenvolvimento das sociedades mostramos, também a partir de Karl Marx, que o trabalhador é separado dos meios de produção que foram apropriados pelos capitalistas visando mais e mais riqueza, lucro, ganância. De

\footnotetext{
34 Fonte: <https://www.dieese.org.br/boletimdeconjuntura/2018/boletimConjuntura016.html >. Acesso: 01 nov. 2018.

35 Para saber mais: <https://politica.estadao.com.br/blogs/fausto-macedo/os-impactos-dareforma-trabalhista-um-ano-apos-vigencia/>. Acesso: 01 nov. 2018.

${ }^{36}$ Para saber mais: <https://jornalistaslivres.org/proposta-enviada-para-jair-bolsonaro-sobre-areforma-da-previdencia-e-pior-que-a-de-temer/>. Acesso: 01 nov. 2018.
} 
outro lado, quanto mais se desenvolve tal sistema, mais exploração e alienação vivem os trabalhadores. Portanto, a luta de classes nesse âmbito se desenvolve através da disputa pela riqueza produzida pelos trabalhadores, pela apropriação das terras e também das políticas que governos desenvolvem e que podem beneficiar uns e outros, tendendo no capitalismo ao benefício dos empresários, latifundiários, comerciantes, bancos, etc.

No caso brasileiro, no entanto, o desenvolvimento de tais relações - do trabalho com a natureza -, foi marcado pela escravidão indígena e africana nos seus primeiros 388 anos, sendo que após esse período boa parte dos postos de trabalho foram ocupados pelos imigrantes. A desigualdade e a miséria até hoje é tamanha - entre os mais ricos e os mais pobres - que, periodicamente, as forças armadas são chamadas para colocar "ordem" no progresso excludente em que vivemos. E o golpe de 2016, surge desse histórico, agora, no entanto, articulado pelos políticos corruptos, mídia e judiciário tendo os militares e os norte-americanos na retaguarda.

Assim, desde 2016 as perspectivas no âmbito dos direitos sociais da população brasileira vêm sendo de profunda precarização e crescimento da vulnerabilidade. As "reformas" trazidas pelo atual governo Temer, e que serão radicalizadas por Bolsonaro e Guedes, demonstram o incremento do poder do patrão sobre o trabalhador, aumentando sua capacidade de coerção e domínio da força de trabalho. Assim, com a perspectiva de incremento da autonomia negocial do empregado, divide-se o risco e se rebaixa a remuneração do empregado.

A contradição dessas reformas que enfraquecem os direitos trabalhistas e o poder de consumo dos trabalhadores está no rebaixamento econômico desses, que acabam sendo ainda mais precarizados. Cria-se uma círculo vicioso que alimenta a especulação e as atividades financeiras, e especulativas, dilapidando o patrimônio público e as riquezas estratégicas para qualquer projeto soberano de país. O desmantelamento do Estado brasileiro vai à contramão da garantia de direitos à população e é um passo maior para uma crise financeira ainda maior, pois aquelas empresas internacionais que 
veem no Brasil a possibilidade de exploração de recursos naturais (o que temos, ainda, em abundância) e um grande número de trabalhadores a serem explorados pelo capital a baixos custos, diante de qualquer ameaça são as primeiras a "pular fora".

A tentativa de reforma da previdência, pelo governo Michel Temer, depois da reforma trabalhista e de outras medidas buscando reduzir o custo do trabalho, e, ante a sua aliança nefasta contra os trabalhadores e a um projeto de país soberano, se completará com a agenda ultra-neoliberal de Bolsonaro e Guedes. Isso porque, o novo governo, que assume em 2019, não se diferencia na agenda de desmantelamento do Estado brasileiro, com indicações de suprimento de ministérios e indicação de nomes questionáveis para posições de chefia política.

Acreditamos que uma das possibilidades de embate frente essa onda neoliberal e fascista que atinge a sociedade brasileira é a necessidade de um retorno ao trabalho de base pelas forças preocupadas com a situação dos trabalhadores e do futuro de soberania nacional. Trata-se de retornar ao "chão de fábrica" para dialogar com os trabalhadores, buscando criar ou fortalecer consciência de classe; nos bairros, comunidades urbanas e rurais, universidades e escolas, igrejas e clubes diversos. isto, com vistas apreparação para a resistência e, para a problematização das propostas que tal governo fizer nos parlamentos, nos sindicatos e entidades da sociedade civil. Mas, também, ser resistência nos espaços de poder governamental dos estados (governos estaduais) ou das cidades (prefeituras) tencionando e propondo outras possibilidades de ação, de outro projeto político e social e de retomada da esperança na possibilidade de construirmosoutro Brasil, diferente do Brasil da exclusão, miséria, exploração do trabalho e da natureza que vivemos atualmente.

\section{REFERÊNCIAS}

ANDERSON, P. Balanço do neoliberalismo. In: SADER, Emir \& GENTILI, Pablo (Org.) Pós-neoliberalismo: as políticas sociais e o Estado democrático. Rio de Janeiro: Paz e Terra, 1995, p. 9-23. 
O Brasil de Lula. Novos estudos - CEBRAP - n`91. São Paulo: nov. 2011. Disponível em: <http://dx.doi.org/10.1590/S0101-33002011000300002>. Acesso em: 01 nov. 2018.

ANTUNES, R. 0 caracol e sua concha: ensaios sobre a nova morfologia do trabalho. SP: Boitempo, 2005.

DREIFUSS, R. 1964: A conquista do Estado (Ação política, poder e golpe de classe). Petrópolis: Vozes, 1981.

LUKÁCS. Para a ontologia do ser social: o trabalho. Tradução do Prof. Ivo Tonet (UFAL), a partir do texto II Lavoro, primeiro capítulo do segundo tomo de Per uma Ontologia dell'Essere Sociale. Roma: Editori Riuniti, 1981.

FERNANDES, F. A Revolução Burguesa no Brasil. São Paulo: Globo, 2005.

MARX, K; ENGELS, F. Manifesto do Partido Comunista. Porto Alegre: L\&PM, 2002.

O Capital: Crítica da Economia Política: livro I. Tradução de Reginaldo Sant'Anna. Rio de Janeiro: Civilização Brasileira, 2013. 31ª edição.

O capital. Crítica da economia política. Livro $1^{\circ}$, tomo $1,2^{\circ}$ ed. São Paulo: Nova Cultural, 1985. In: SOUZA, J. A. de. O TRABALHO ASSOCIADO EM KARL MARX: Contribuição ao debate acerca do cooperativismo e da transição. Dissertação mestrado) - Universidade Federal de Santa Catarina, Programa de Pós-Graduação em Sociologia Política do Centro de Filosofia e Ciências Humanas, Florianópolis, 2008.

SOUZA, J. A. de. O TRABALHO ASSOCIADO EM KARL MARX: Contribuição ao debate acerca do cooperativismo e da transição. Dissertação mestrado) Universidade Federal de Santa Catarina, Programa de Pós-Graduação em Sociologia Política do Centro de Filosofia e Ciencias Humanas, Florianópolis, 2008.

SOUZA, A. R. Economia Solidária: um movimento nascente da crise do trabalho. In: SOUZA, A. R. de; CUNHA, G. C.; DAKUZAKU, R. Y (Orgs.). Uma outra economia é possível: Paul Singer e a economia solidária. São Paulo: Contexto, 2003. 